\title{
INTUITIONISTIC FUZZY GENERALIZED PROBABILISTIC ORDERED WEIGHTED AVERAGING OPERATOR AND ITS APPLICATION TO GROUP DECISION MAKING
}

\author{
Shouzhen $Z_{E N G}$ a, b, Weihua SUc, Chonghui ZHANG ${ }^{\mathrm{d}}$ \\ ${ }^{a}$ School of Business, Ningbo University, 315211 Ningbo, China \\ ${ }^{b}$ College of Compute and Information, Zhejiang Wanli University, 315100 Ningbo, China \\ ${ }^{c}$ College of Mathematics and Statistics, Zhejiang University of Finance and Economics, \\ 310018 Hangzhou, China \\ ${ }^{d}$ College of Statistics and Mathematics, Zhejiang Gongshang University, 310018 Hangzhou, China
}

Received 22 August 2012; accepted 08 July 2013

\begin{abstract}
In this paper, we present the intuitionistic fuzzy generalized probabilistic ordered weighted averaging (IFGPOWA) operator. It is a new aggregation operator that uses generalized means in a unified model between the probability and the OWA operator. The main advantage of this new operator is that it is able to deal with probabilities (objective information) and ordered weighted averages (subjective information) in the same formulation. Moreover, it is also able to deal with uncertain environments that can be assessed with intuitionistic fuzzy numbers. Furthermore, it uses generalized means providing a very general formulation that includes a wide range of situations. We study some of its main properties and particular cases such as the generalized intuitionistic fuzzy ordered weighted averaging (GIFOWA) operator and intuitionistic fuzzy probabilistic ordered weighted averaging (IFPOWA) operator. We end the paper by applying the new operator to a group decision making problem concerning the selection of investments.
\end{abstract}

Keywords: probability, OWA operator, intuitionistic fuzzy set, group decision making.

JEL Classification: A12, C44, C60, D81, D89.

\section{Introduction}

Different types of aggregation operators are found in the literature for aggregating the information (Beliakov et al. 2007; Calvo et al. 2002; Xu, Da 2003). One of the most popular aggregation method is probabilistic aggregation (Gil-Lafuente, Merigó 2010; Merigó 2012a, $2012 b$ ). The use of probabilities permits an objective modelization of the decision making

Corresponding author Shouzhen Zeng

E-mail: zszzxl@163.com 
problem and its uncertainties under analysis. Another interesting type of aggregation operators is the ordered weighted averaging (OWA) operator (Yager 1988). It provides a parameterized family of aggregation operators that include as special cases the maximum, the minimum and the average. The OWA operator is very useful for representing the attitudinal character of the decision-maker in decision making. Since its appearance, the OWA operator has been used in a wide range of applications (Chen, Zhou 2011; Cheng et al. 2009; Liu 2008, 2011; Liu, Jin 2012a, 2012b, 2012c; Liu et al. 2012; Liu, Su 2010; Merigó 2010, 2012b; Merigó, Casanovas 2010, 2011a, 2011b; Merigó, Gil-Lafuente 2010; Wei 2010a; Xu, Wang 2011, 2012; Xu 2005, 2007a; Xu, Chen 2008; Xu, Xia 2010; Xu, Yager 2006; Yager 2007; Zarghami, Szidarovszky 2009; Zeng, Su 2011, 2012; Zeng et al. 2012; Zhou, Chen 2010, 2011).

Recently, Merigó (2011a, 2012b) has suggested a new model called the probabilistic OWA (POWA) operator, which unifies the OWA operator and the probability in the same formulation. The POWA operator provides a parameterized family of aggregation operators between the minimum and maximum that includes the probability in the aggregation process. Its main advantage is that it can represent the degree of importance of the probability and the OWA in the aggregation. Thus, we can use the attitudinal character of the decision maker and the probabilistic information of the specific problem considered. Note that by using probabilities, we assume that we have some kind of information that permits us to forecast the future results. Especially, we focus on the concept of objective probabilities where we assume that the probabilities are formed by some type of neutral experiment. The POWA operator has received much attention from researchers. For example, Merigó et al. (2012) have further generalized the POWA operator by using generalized means, obtaining the generalized probabilistic OWA (GPOWA) operator, which includes a wide range of particular cases including the generalized OWA (GOWA) operator (Yager 2004) and the POWA. It has also been developed to accommodate interval numbers (Merigó, Wei 2011; Merigó 2011b), fuzzy numbers (2011a), intuitionistic fuzzy set (Wei, Merigó 2012) and distance measures (Zeng et al. 2013).

Usually, when using the POWA and the GPOWA operators, it is assumed that the available information is clearly known and can be assessed with exact numbers. However, in the real-life world, due to the increasing complexity of the socioeconomic environment and the lack of knowledge or data about the problem domain, exact numbers are sometimes unavailable. Thus, the input arguments may be vague or fuzzy in nature. Atanassov (1986) defined the notion of an intuitionistic fuzzy set (IFS), whose basic elements are intuitionistic fuzzy numbers (IFNs) (Xu, Yager 2006; Xu 2007a), each of which are composed of a membership degree and a nonmembership degree. In many practical situations, particularly in the process of group decision making under uncertainty, the experts may come from different research areas and thus have different backgrounds and levels of knowledge, skills, experience, and personality. The experts may not have enough expertise or possess a sufficient level of knowledge to precisely express their preferences over the objects, and then, they usually have some uncertainty in providing their preferences, which makes the results of cognitive performance exhibit the characteristics of affirmation, negation, and hesitation. In such cases, the data or preferences given by the experts may be appropriately expressed in IFNs. For example, in multi-criteria decision 
making problems, such as personnel evaluations, medical diagnosis, project investment analysis, etc., each IFN provided by the expert can be used to express both the degree for an alternative satisfying a criterion and the degree for the alternative not satisfying the criterion. The IFN is highly useful in depicting uncertainty and vagueness of an object, and thus can be used as a powerful tool to express data information under various different fuzzy environments which has attracted great attentions (Atanassov, Gargov 1989; Atanassov et al. 2005; Boran et al. 2009; Li 2008; Liu 2007; Szmidt, Kacprzyk 2003; Tan, Chen 2010; Wei 2008, 2010b; Xu, Wang 2012; Xu 2007a, 2007b, 2007c, 2010a, 2010b, 2011; Xu, Cai 2009, 2010; Xu, Xia 2010; Xu, Yager 2006; Ye 2009, 2010; Zeng 2013).

Despite the importance of the POWA operator and the IFS in the decision making, we haven't seen any study on the aggregation intuitionistic fuzzy information with the POWA operator. So, in this paper, we shall generalize the POWA operator to the intuitionistic fuzzy setting and present the intuitionistic fuzzy generalized probabilistic ordered weighted averaging (IFGPOWA) operator. The IFGPOWA unifies the probability and the OWA in the same formulation. Thus, we are able to consider objective information (probabilistic) and the attitudinal character of the decision maker in the same formulation. Moreover, it is also able to deal with an uncertain environment that can be assessed with intuitionistic fuzzy numbers. Furthermore, it uses generalized means providing a more robust formulation of the model. With this generalization, we obtain a wide range of intuitionistic fuzzy aggregation operators such as the maximum, the minimum, the GIFOWA operator (Zhao et al. 2010), the intuitionistic fuzzy arithmetic probabilistic aggregation (IFA-PA), the intuitionistic fuzzy arithmetic OWA (IFA-OWA), the intuitionistic fuzzy probabilistic OWA (IFPOWA) and the intuitionistic fuzzy geometric probabilistic ordered weighted geometric averaging (IFG-POWGA) operator.

The applicability of IFGPOWA is very broad. In this paper, we apply it to a decision making problem regarding the selection of investments, so that the decision-maker knows these different results could happen and thus selects the one in accordance with his/her interests. Thus, we show that depending on the particular case used, results may lead to different decisions. The main problem that we identify is that we do not have one model that yields the best decision, because we are dealing with uncertainty. Obviously, given these types of problems, the best way to assess information is through a general model that includes different methods in the same formulation, although it cannot identify one method with the best decision. Therefore, this general model (IFGPOWA) at least provides potential results that may occur in the decision problem, so that the decision-maker knows these different results could happen and thus selects the one in accordance with his/her interests.

This paper is organized as follows. In Section 1, we briefly review some basic concepts about IFS, the OWA, the POWA and the GPOWA operator. In Section 2 we introduce the IFGPOWA operator, and different families of IFGPOWA operators are analyzed in Section 3. In Section 4 we develop an approach to group decision making based on the IFGPOWA operator and present a numerical example in Section 5. The last Section summarizes the main conclusions of the paper. 


\section{Preliminaries}

In this Section, we briefly review some basic concepts about intuitionistic fuzzy set, the OWA, the POWA and the GPOWA operator.

\subsection{Intuitionistic fuzzy set}

Let $X$ be a universe of discourse, then a fuzzy set:

$$
A=\left\{<x, \mu_{A}(x)>\mid x \in X\right\},
$$

defined by Zadeh (1965) is characterized by a membership function $\mu_{A}: X \rightarrow[0,1]$, where $\mu_{A}(x)$ denotes the degree of membership of the element $x$ to the set $A$.

Atanassov (1986) introduced a generalized fuzzy set called intuitionistic fuzzy set (IFS), shown as follows:

An IFS in $X$ is given by:

$$
A=\left\{<x, \mu_{A}(x), v_{A}(x)>\mid x \in X\right\},
$$

which is characterized by a membership function $\mu_{A}: X \rightarrow[0,1]$ and a non-membership function $v_{A}: X \rightarrow[0,1]$, with the condition:

$$
0 \leq \mu_{A}(x)+v_{A}(x) \leq 1, \forall x \in X,
$$

where the numbers $\mu_{A}(x)$ and $v_{A}(x)$ represent, respectively, the degree of membership and the degree of non-membership of the element $x$ to the set $A$.

For each IFS $A$ in $X$, if:

$$
\pi_{A}(x)=1-\mu_{A}(x)-v_{A}(x), \forall x \in X,
$$

then $\pi_{A}(x)$ is called the indeterminacy degree or hesitation degree of $x$ to $A$. Especially, if

$$
\pi_{A}(x)=1-\mu_{A}(x)-v_{A}(x)=0, \forall x \in X,
$$

then, the intuitionistic fuzzy set $A$ is reduced to a common fuzzy set.

For convenience, we called $\alpha=\left(\mu_{\alpha}, v_{\alpha}\right)$ an intuitionistic fuzzy number (IFN) (Xu, Yager 2006; Xu 2007a), where $\mu_{\alpha} \in[0,1], v_{\alpha} \in[0,1]$, and $\mu_{\alpha}+v_{\alpha} \leq 1$. Additionally $S(\alpha)=\mu_{\alpha}-v_{\alpha}$ and $H(\alpha)=\mu_{\alpha}+v_{\alpha}$ are called the score and accuracy degree of $\alpha$, respectively.

For any three intuitionistic fuzzy numbers (IFNs) $\alpha=\left(\mu_{\alpha}, v_{\alpha}\right), \alpha_{1}=\left(\mu_{\alpha_{1}}, v_{\alpha_{1}}\right)$ and $\alpha_{2}=\left(\mu_{\alpha_{2}}, v_{\alpha_{2}}\right)$, the following operational laws are valid (Xu, Yager 2006; Xu 2007a).

(1) $\alpha_{1} \oplus \alpha_{2}=\left(\mu_{\alpha_{1}}+\mu_{\alpha_{2}}-\mu_{\alpha_{1}} \cdot \mu_{\alpha_{2}}, v_{\alpha_{1}} \cdot v_{\alpha_{2}}\right)$;

(2) $\lambda \alpha=\left(1-\left(1-\mu_{\alpha}\right)^{\lambda}, v_{\alpha}^{\lambda}\right)$;

(3) $\alpha^{\lambda}=\left(\mu_{\alpha}^{\lambda}, 1-\left(1-v_{\alpha}\right)^{\lambda}\right)$.

To compare two IFNs $\alpha_{1}$ and $\alpha_{2}$, Xu and Yager (2006) introduced an order relation in the following:

- If $S\left(\alpha_{1}\right)<S\left(\alpha_{2}\right)$, then $\alpha_{1}<\alpha_{2}$; 
- If $S\left(\alpha_{1}\right)=S\left(\alpha_{2}\right)$, then

(1) If $H\left(\alpha_{1}\right)<H\left(\alpha_{2}\right)$, then $\alpha_{1}<\alpha_{2}$;

(2) If $H\left(\alpha_{1}\right)=H\left(\alpha_{2}\right)$, then $\alpha_{1}=\alpha_{2}$.

\subsection{The OWA Operator}

The OWA operator (Yager 1988) is an aggregation operator that provides a parameterized family of aggregation operators between the minimum and the maximum. It can be defined as follows:

Definition 1. An OWA operator of dimension $n$ is a mapping OWA: $R^{n} \rightarrow R$ that has an associated weighting $W$ with $w_{j} \in[0,1]$ and $\sum_{j=1}^{n} w_{j}=1$, such that:

$$
\operatorname{OWA}\left(a_{1}, a_{2} \ldots, a_{n}\right)=\sum_{j=1}^{n} w_{j} b_{j}
$$

where $b_{j}$ is the $j$ th largest of the $a_{i}$.

The OWA operator aggregates the information according to the attitudinal character (or degree of orness) of the decision maker (Merigó, Gil-Lafuente 2010; Yager 1988). The attitudinal character is represented according to the following formula:

$$
\alpha(W)=\sum_{j=1}^{n} w_{j}\left(\frac{n-j}{n-1}\right) .
$$

Note that $\alpha(W) \in[0,1]$. The more weight $W$ is located close to the top, the closer $\alpha$ is to 1 . In decision making problems, the degree of orness is useful for representing the attitudinal character of the decision-maker by using it as the degree of optimism or pessimism.

\subsection{The POWA operator}

The POWA operator is an aggregation operator that provides a parameterized family of aggregation operators between the maximum and the minimum that unifies probabilities and OWA in the same formulation (Merigó 2011a, 2012b). Its main advantage is that it is able to include both concepts considering the degree of importance of each case in the problem. It is defined as follows.

Definition 2. A POWA operator of dimension $n$ is a mapping POWA: $R^{n} \rightarrow R$ that has an associated weighting vector $W$ with $w_{j} \in[0,1]$ and $\sum_{j=1}^{n} w_{j}=1$, according to the following
formula:

$$
\operatorname{POWA}\left(a_{1}, a_{2} \ldots, a_{n}\right)=\sum_{j=1}^{n} \hat{p}_{j} b_{j}
$$

where $b_{j}$ is the $j$ th largest of the $a_{i}$, each argument $a_{i}$ has an associated probability $p_{i}$ with $\sum_{i=1}^{n} p_{i}=1$ and $p_{i} \in[0,1], \hat{p}_{j}=\gamma w_{j}+(1-\gamma) p_{j}$ with $\gamma \in[0,1]$ and $p_{j}$ is the probability $p_{i}$ ordered according to $b_{j}$, that is, according to the $j$ th largest of the $a_{i}$. 
Note that it is also possible to formulate the POWA operator separating the part that strictly affects the OWA operator and the part that affects the probabilities. This representation is useful to see both models in the same formulation but it does not seem to be as a unique equation unifying both models.

Definition 3. A POWA operator of dimension $n$ is a mapping POWA: $R^{n} \rightarrow R$ that has an associated weighting vector $W$ with $w_{j} \in[0,1]$ and $\sum_{j=1}^{n} w_{j}=1$ and a probabilistic vector $P$, with $p_{i} \in[0,1]$ and $\sum_{i=1}^{n} p_{i}=1$, such that:

$$
\operatorname{POWA}\left(a_{1}, a_{2} \ldots, a_{n}\right)=\gamma \sum_{j=1}^{n} w_{j} b_{j}+(1-\gamma) \sum_{i=1}^{n} p_{i} a_{1}
$$

where $b_{j}$ is the $j$ th largest of the argument $a_{i}$ and $\gamma \in[0,1]$.

\subsection{The GPOWA operator}

The generalized probabilistic OWA (GPOWA) operator (Merigó et al. 2012) uses generalized means providing a more complete representation that includes a wide range of particular cases. It can be defined as follows.

Definition 4. A GPOWA operator of dimension $n$ is a mapping GPOWA: $R^{n} \rightarrow R$ that has an associated weighting vector $W$ with $w_{j} \in[0,1]$ and $\sum_{j=1}^{n} w_{j}=1$, according to the following formula:

$$
\operatorname{GPOWA}\left(a_{1}, a_{2} \ldots, a_{n}\right)=\gamma\left(\sum_{j=1}^{n} w_{j} b_{j}^{\lambda}\right)^{1 / \lambda}+(1-\gamma)\left(\sum_{i=1}^{n} p_{i} a_{i}^{\delta}\right)^{1 / \delta}
$$

where $b_{j}$ is the $j$ th largest of the argument $a_{i}, \gamma \in[0,1], \lambda$ and $\delta$ are parameters such that $\lambda, \delta \in(-\infty,+\infty)-\{0\}$.

By choosing a different manifestation in the weighting vector, we are able to obtain a wide range of particular types of GPOWA operators. Especially, when $\gamma=0$, we get the probabilistic aggregation (Merigó 2012a), and if $\gamma=1$, we get the generalized OWA (GOWA) operator. When $\lambda=\delta=1$, we get the POWA operator (Merigó 2012b). However, the POWA and the GPOWA are mainly used to aggregate the data taking the form of exact numerical, in what follows, we shall extend them to accommodate the situation in which the input data is provided with IFNs.

\section{The intuitionistic fuzzy generalized probabilistic OWA operator}

In some decision making processes, the decision maker cannot assess the information of attributes with crisp numbers because of the vague or imprecise knowledge. At present several useful tools have been introduced to depict uncertain information such as fuzzy set (Zadeh 1965), intuitionistic fuzzy set (IFS) (Atanassov 1986), linguistic information (Herrera, 
Herrera-Viedma 2000). Among all the tools, IFS is used more extensively since each element in the IFS being characterized by a membership degree and a non-membership degree and this leads to IFS is more appropriate to deal with the uncertainty and vagueness. So, in this Section, we shall investigate the POWA operator under intuitionistic fuzzy environments and introduce the intuitionistic fuzzy generalized probabilistic OWA (IFGPOWA) operator.

Let $\Omega$ be the set of all IFNs, we give the definition of the IFGPOWA as follows:

Definition 5. Let $\alpha_{i}=\left(\mu_{i}, v_{i}\right)(i=1,2, \ldots, n)$ be a collection of IFNs, an IFGPOWA operator of dimension $n$ is a mapping IFGPOWA: $\Omega^{n} \rightarrow \Omega$ that has an associated weighting vector $W$ with $w_{j} \in[0,1]$ and $\sum_{j=1}^{n} w_{j}=1$ and a probabilistic vector $P$, with $p_{i} \in[0,1]$ and $\sum_{i=1}^{n} p_{i}=1$, such that:

$$
\operatorname{IFGPOWA}\left(\alpha_{1}, \alpha_{2} \ldots, \alpha_{n}\right)=\gamma\left(\sum_{j=1}^{n} w_{j} \beta_{j}^{\lambda}\right)^{1 / \lambda}+(1-\gamma)\left(\sum_{i=1}^{n} p_{i} \alpha_{i}^{\delta}\right)^{1 / \delta},
$$

where $\beta_{j}$ is the $j$ th largest of the argument $\alpha_{i}, \beta \in[0,1], \lambda$ and $\delta$ are parameters such that $\lambda, \delta \in(-\infty,+\infty)-\{0\}$.

In the following, we are going to give a simple example of how to aggregate with the IFGPOWA operator.

Example 1. Assume the following arguments in an aggregation process: $((0.5,0.3),(0.4$, $0.5),(0.8,0.1),(0.6,0.3))$. Assume the following weighting vector $W=(0.2,0.2,0.3,0.3)$ and the following probabilistic weighting vector $P=(0.3,0.2,0.4,0.1)$. Note that the probabilistic information has a degree of importance of $70 \%$ while the weighting vector $W$ a degree of $30 \%$, and without loss of generality, suppose $\lambda=\delta=2$, then

$$
\begin{aligned}
& I F G P O W A=0.3 \times\left(0.2 \times(0.8 .0 .1)^{2}+0.2 \times(0.6,0.3)^{2}+0.3 \times(0.5,0.3)^{2}+0.3 \times(0.4,0.5)^{2}\right)^{1 / 2}+ \\
& 0.7 \times\left(0.2 \times(0.5,0.3)^{2}+0.2 \times(0.4,0.5)^{2}+0.3 \times(0.8 .0 .1)^{2}+0.3 \times(0.6,0.3)^{2}\right)^{1 / 2}=(0.63,0.34) .
\end{aligned}
$$

From a generalized perspective of the reordering step, we can distinguish between the descending IFGPOWA (DIFGPOWA) operator and the ascending IFGPOWA (AIFGPOWA) operator by using $w_{j}=w_{n-j+1}^{*}$, where $w_{j}$ is the jth weight of the DIFGPOWA and $w_{n-j+1}^{*}$ the $j$ th weight of the AIFGPOWA operator.

The IFGPOWA is monotonic, bounded and idempotent. It is monotonic because if $\alpha_{i} \geq \alpha_{i}^{\prime}$ for all $i$, then IFGPOWA $\left(\alpha_{1}, \alpha_{2}, \ldots, \alpha_{n}\right) \geq \operatorname{IFGPOWA}\left(\alpha_{1}{ }^{\prime}, \alpha_{2}{ }^{\prime}, \ldots, \alpha_{n}{ }^{\prime}\right)$. It is bounded because the IFGPOWA aggregation is delimitated by the minimum and the maximum. That is, $\operatorname{Min}\left(\alpha_{i}\right) \leq \operatorname{IFGPOWA}\left(\alpha_{1}, \ldots, \alpha_{n}\right) \leq \operatorname{Max}\left(\alpha_{i}\right)$. It is idempotent because if $\alpha_{1}=\alpha$ for all $i$, $\operatorname{IFGPOWA}\left(\alpha_{1}, \alpha_{2}, \ldots, \alpha_{n}\right)=\alpha$.

\section{Families of IFGPOWA operators}

In the following we analyze different families of IFGPOWA operators. The main advantage is that we can consider a wide range of particular cases that can be used in the IFGPOWA 
operator leading to different results. Thus, we are able to provide a more complete representation of the aggregation process.

The IFGPOWA operator provides a parameterized family of aggregation operators. Basically, we distinguish between the families found in the coefficient $\gamma$ in the parameters $\lambda$ and $\delta$ and in the weighting vector $W$. If we analyze the coefficient $\gamma$, we get the following:

- If $\gamma=1$, we get the GIFOWA operator.

- If $\gamma=0$, we get the intuitionistic fuzzy generalized probabilistic approach.

The more $\gamma$ approaches to 1 , the more importance we give to the GIFOWA operator, and vice versa. If we analyze different values of the parameter $\lambda$ and $\delta$, we obtain another group of particular cases such as the IFPOWA operator, the intuitionistic fuzzy geometric probabilistic ordered weighted geometric averaging (IFG-POWGA) operator, the intuitionistic fuzzy harmonic probabilistic ordered weighted harmonic averaging (IFH-POWHA) operator and the intuitionistic fuzzy quadratic probabilistic ordered weighted quadratic averaging (IFQ-POWQA) operator.

Remark 1. When $\lambda=\delta=1$, the IFGPOWA operator becomes the IFPOWA operator:

$$
\operatorname{IFPOWA}\left(\alpha_{1}, \alpha_{2} \ldots, \alpha_{n}\right)=\gamma \sum_{j=1}^{n} w_{j} \beta_{j}+(1-\gamma) \sum_{i=1}^{n} P_{i} \alpha_{i} .
$$

Note that in this case, if $w_{j}=1 / n$ for all $j$, we get the intuitionistic fuzzy arithmetic probabilistic aggregation (IFA-PA). And if $p_{i}=1 / n$ for all $i$, we get the intuitionistic fuzzy arithmetic OWA (IFA-OWA) operator.

Remark 2. When $\lambda \rightarrow 0$ and $\delta \rightarrow 0$, the IFGPOWA operator becomes the intuitionistic fuzzy geometric probabilistic ordered weighted geometric averaging (IFG-POWGA) operator.

$$
\operatorname{IFGPOWGA}\left(\alpha_{1}, \alpha_{2} \ldots, \alpha_{n}\right)=\gamma \prod_{j=1}^{n} w_{j}^{\beta_{j}}+(1-\gamma) \prod_{i=1}^{n} P_{i}^{\alpha_{i}} .
$$

Note that if $w_{j}=1 / n$ for all $j$, we get the intuitionistic fuzzy geometric probabilistic geometric aggregation (IFG-PGA). Note also that if $p_{i}=1 / n$ for all $i$ we get the intuitionistic fuzzy the geometric probability OWGA (IFG-OWGA) operator.

Remark 3. When $\lambda=\delta=-1$, we get the intuitionistic fuzzy harmonic probabilistic ordered weighted harmonic averaging (IFH-POWHA) operator:

$$
\operatorname{IFHPOWHA}\left(\alpha_{1}, \alpha_{2} \ldots, \alpha_{n}\right)=\gamma \frac{1}{\sum_{j=1}^{n} \frac{w_{j}}{\beta_{j}}}+(1-\gamma) \frac{1}{\sum_{j=1}^{n} \frac{P_{i}}{\alpha_{i}}}
$$

If $w_{j}=1 / n$ for all $j$, we get the intuitionistic fuzzy harmonic probabilistic harmonic aggregation (IFH-PHA). Note also that if $p_{i}=1 / n$ for all $i$, we get the intuitionistic fuzzy harmonic probability OWHA (IFH-OWHA) operator.

Remark 4. When $\lambda=\delta=2$, we get the intuitionistic fuzzy quadratic probabilistic ordered weighted quadratic averaging (IFQ-POWQA) operator:

$$
\operatorname{IFQPOWQA}\left(\alpha_{1}, \alpha_{2} \ldots, \alpha_{n}\right)=\gamma\left(\sum_{j=1}^{n} w_{j} \beta_{j}^{2}\right)^{1 / 2}+(1-\gamma)\left(\sum_{i=1}^{n} P_{i} \alpha_{i}^{2}\right)^{1 / 2} .
$$


Note that if $w_{j}=1 / n$ for all $j$, we get the intuitionistic fuzzy quadratic probabilistic quadratic aggregation (IFQ-PQA). Note also that if $p_{i}=1 / n$ for all $i$, we get the intuitionistic fuzzy quadratic probability OWQA (IFQ-OWQA)operator.

Remark 5. When $\lambda=\delta=3$, we get the intuitionistic fuzzy cubic probabilistic ordered weighted cubic averaging (IFC-POWCA) operator.

$$
\operatorname{IFCPOWCA}\left(\alpha_{1}, \alpha_{2} \ldots, \alpha_{n}\right)=\gamma\left(\sum_{j=1}^{n} w_{j} \beta^{3}\right)^{1 / 3}+(1-\gamma)\left(\sum_{i=1}^{n} P_{i} \alpha^{3}{ }_{i}^{1 / 3} .\right.
$$

Note that if $w_{j}=1 / n$ for all $j$, we get the intuitionistic fuzzy cubic probabilistic cubic aggregation (IFC-PCA). And if $p_{i}=1 / n$ for all $i$, we get the intuitionistic fuzzy cubic probability OWCA (IFC-POWCA) operator.

Remark 6. When $\lambda \rightarrow \infty$ and $\delta \rightarrow \infty$, we get the maximum.

Remark 7. When $\lambda \rightarrow-\infty$ and $\delta \rightarrow-\infty$, we get the minimum.

Remark 8. Moreover, we can use different values in $\lambda$ and $\delta$. For example, if $\lambda=2$ and $\delta=3$, we form the intuitionistic fuzzy cubic probabilistic ordered weighted quadratic averaging (IFC-POWQA) operator:

$$
\operatorname{IFCPOWQA}\left(\alpha_{1}, \alpha_{2} \ldots, \alpha_{n}\right)=\gamma\left(\sum_{j=1}^{n} w_{j} \beta_{j}^{2}\right)^{1 / 2}+(1-\gamma)\left(\sum_{i=1}^{n} w_{i} \alpha^{3}{ }_{i}\right)^{1 / 3} .
$$

Remark 9. If we analyse the weighting vector, then, we find the following cases:

- The intuitionistic fuzzy probabilistic maximum $\left(w_{1}=1\right.$ and $w_{j}=0$, for all $j \neq 1$ ).

- The intuitionistic fuzzy probabilistic minimum $\left(w_{n}=1\right.$ and $w_{j}=0$, for all $\left.j \neq n\right)$.

- The intuitionistic fuzzy generalized mean (IFGM) $\left(w_{j}=1 / n\right.$ and $p_{i}=1 / n$ for all $\left.i, j\right)$.

- The step-IFGPOWA operator $\left(w_{k}=1\right.$ and $w_{j}=0$, for all $\left.j \neq k\right)$.

- The centered-IFGPOWA operator (if it is symmetric, strongly decaying from the center to the maximum and the minimum, and inclusive).

- The olympic-IFGPOWA operator $\left(w_{1}=w_{n}=0\right.$ and for all others $\left.w_{j}=1 /(n-2)\right)$.

- The median-IFGPOWA operator (if $n$ is odd we assign $w_{(n+1) / 2}=1$ and $w_{j}=0$ for all others. If $n$ is even, then we assign $\left.w_{n / 2}=w_{(n / 2)+1}=0.5\right)$.

Remark 10. We could develop a lot of other families of IFGPOWA weights in a similar way as it has been developed in a lot of studies (Merigó, Casanovas 2011a, 2011b; Merigó, Gil-Lafuente 2010; Merigó et al. 2012; Xu, Chen 2008; Zeng, Su 2011).

\section{An approach to group decision making based on the IFGPOWA operator}

The IFGPOWA operator can be applied in a wide range of disciplines because all the studies that use the probability or the OWA operator can be revised and extended with this new approach. The reason is that we can always reduce it to the classical case where we only use probabilities or OWA operators. Thus, all disciplines that use these types of statistical techniques can be revised with this new approach (Yager 1996, 2006). For example, we 
could mention statistics, economics, engineering, business, physics, biology, chemistry and medicine. In this paper, we consider a group decision making application in the selection of investments. The process to follow in the selection of investments with the IFGPOWA operator in group decision making can be summarized as follows.

Step 1. Let $A=\left\{A_{1}, A_{2}, \ldots, A_{m}\right\}$ be a discrete set of alternatives, and $G=\left\{G_{1}, G_{2}, \ldots, G_{n}\right\}$ be the set of attributes. Let $E=\left\{e_{1}, e_{2}, \ldots, e_{t}\right\}$ be the set of decision makers (whose weight vector is $\left.V=\left(v_{1}, v_{2}, \ldots, v_{t}\right), v_{k} \geq 0, \sum_{k=1}^{t} v_{k}=1\right)$. Each decision maker provides his own payoff matrix $\left(\alpha_{i j}^{(k)}\right)_{m \times n}$.

Step 2. Use the intuitionistic fuzzy weighted averaging (IFWA) operator (Xu 2007a) to aggregate the information of the decision makers $E$ by using the weighting vector $V$. The result is the fuzzy collective payoff matrix $\left(\alpha_{i j}\right)_{m \times n}$, where:

$$
\alpha_{i j}=v_{1} \alpha_{i j}^{(1)} \oplus v_{2} \alpha_{i j}^{(2)} \oplus \ldots \oplus v_{k} \alpha_{i j}^{(k)}, i=1,2, \ldots, m, j=1,2, \ldots, n .
$$

Step 3. Calculate the weighting vector $W$ and probabilistic vector $P$ to be used in the aggregation. Note that $W=\left(w_{1}, w_{2}, \ldots, w_{n}\right)$ such that $\sum_{j=1}^{n} w_{j}=1$ and $w_{j} \in[0,1]$ and $P=\left(p_{1}, p_{2}, \ldots, p_{n}\right)$ such that $\sum_{i=1}^{n} p_{i}=1$ and $p_{i} \in[0,1]$.

Step 4. Calculate the aggregated results using the IFGPOWA operator explained in Eq. (11). Note that it is possible to consider a wide range of IFGPOWA operators, such as those described in Sections 4.

Step 5. Adopt decisions according to the results found in the previous steps. Select the alternative/s that provides the best result/s. Moreover, establish an ordering or a ranking of the alternatives from the most to the least preferred alternative to enable consideration of more than one selection.

\section{Illustrative example}

In the following, we are going to develop a numerical example of the new approach. We analyze the results obtained by using different types of IFGPOWA operators and we see that depending on the aggregation operator used, the decision may be different.

Assume that a company wants to invest some money in another company. After analyzing the information, the board of directors considers six possible investments to follow:

(1) Invest in a chemical company called $A_{1}$;

(2) Invest in a food company called $A_{2}$;

(3) Invest in a computer company called $A_{3}$;

(4) Invest in a car company called $A_{4}$;

(5) Invest in a furniture company called $A_{5}$;

(6) Invest in a pharmaceutical company called $A_{6}$.

In order to evaluate these investments, the group of experts considers that the key factor is the economic situation of the next year. Then, depending on the situation, the expected 
benefits for the company will be different. The experts have considered five possible situations for the next year:

(1) $G_{1}-$ Negative growth rate;

(2) $G_{2}-$ Growth rate near 0;

(3) $G_{3}$ - Low growth rate;

(4) $G_{4}$ - Medium growth rate;

(5) $G_{5}$ - High growth rate.

The group of company experts is constituted by three persons, each offering their own opinions regarding the results obtained with each investment. As the environment is very uncertain, the group of experts in the company needs to assess the available information by using IFNs. The expected results given in the form of IFNs depending on the situation and the alternative are shown in Tables 1-3.

Table 1. Intuitionistic fuzzy payoff matrix - Expert 1

\begin{tabular}{cccccc}
\hline & $G_{1}$ & $G_{2}$ & $G_{3}$ & $G_{4}$ & $G_{5}$ \\
\hline$A_{1}$ & $(0.5,0.4)$ & $(0.5,0.3)$ & $(0.2,0.6)$ & $(0.4,0.4)$ & $(0.5,0.4)$ \\
\hline$A_{2}$ & $(0.7,0.3)$ & $(0.7,0.3)$ & $(0.6,0.2)$ & $(0.6,0.2)$ & $(0.7,0.2)$ \\
\hline$A_{3}$ & $(0.5,0.4)$ & $(0.6,0.4)$ & $(0.6,0.2)$ & $(0.5,0.3)$ & $(0.6,0.3)$ \\
\hline$A_{4}$ & $(0.7,0.2)$ & $(0.7,0.2)$ & $(0.4,0.2)$ & $(0.5,0.2)$ & $(0.4,0.4)$ \\
\hline$A_{5}$ & $(0.4,0.3)$ & $(0.5,0.2)$ & $(0.4,0.5)$ & $(0.4,0.6)$ & $(0.3,0.4)$ \\
\hline$A_{6}$ & $(0.6,0.2)$ & $(0.4,0.3)$ & $(0.7,0.3)$ & $(0.6,0.3)$ & $(0.5,0.4)$ \\
\hline
\end{tabular}

Table 2. Intuitionistic fuzzy payoff matrix - Expert 2

\begin{tabular}{cccccc}
\hline & $G_{1}$ & $G_{2}$ & $G_{3}$ & $G_{4}$ & $G_{5}$ \\
\cline { 2 - 6 }$A_{1}$ & $(0.5,0.5)$ & $(0.8,0.2)$ & $(0.6,0.2)$ & $(0.7,0.2)$ & $(0.6,0.3)$ \\
\hline$A_{2}$ & $(0.4,0.5)$ & $(0.6,0.2)$ & $(0.7,0.3)$ & $(0.3,0.4)$ & $(0.7,0.1)$ \\
\hline$A_{3}$ & $(0.5,0.2)$ & $(0.7,0.2)$ & $(0.8,0.1)$ & $(0.7,0.1)$ & $(0.3,0.4)$ \\
\hline$A_{4}$ & $(0.6,0.2)$ & $(0.3,0.4)$ & $(0.5,0.5)$ & $(0.6,0.2)$ & $(0.4,0.5)$ \\
\hline$A_{5}$ & $(0.7,0.1)$ & $(0.5,0.1)$ & $(0.3,0.2)$ & $(0.4,0.3)$ & $(0.7,0.2)$ \\
\hline$A_{6}$ & $(0.7,0.3)$ & $(0.8,0.2)$ & $(0.6,0.3)$ & $(0.6,0.2)$ & $(0.5,0.3)$ \\
\hline
\end{tabular}

Table 3. Intuitionistic fuzzy payoff matrix - Expert 3

\begin{tabular}{cccccc}
\hline & $G_{1}$ & $G_{2}$ & $G_{3}$ & $G_{4}$ & $G_{5}$ \\
\hline$A_{1}$ & $(0.5,0.3)$ & $(0.7,0.2)$ & $(0.5,0.3)$ & $(0.5,0.4)$ & $(0.7,0.3)$ \\
\hline$A_{2}$ & $(0.6,0.3)$ & $(0.6,0.2)$ & $(0.7,0.2)$ & $(0.8,0.1)$ & $(0.5,0.4)$ \\
\hline$A_{3}$ & $(0.7,0.3)$ & $(0.4,0.4)$ & $(0.6,0.3)$ & $(0.4,0.2)$ & $(0.6,0.3)$ \\
\hline$A_{4}$ & $(0.4,0.4)$ & $(0.6,0.2)$ & $(0.4,0.2)$ & $(0.7,0.2)$ & $(0.6,0.2)$ \\
\hline$A_{5}$ & $(0.7,0.2)$ & $(0.7,0.3)$ & $(0.6,0.1)$ & $(0.7,0.3)$ & $(0.5,0.3)$ \\
\hline$A_{6}$ & $(0.5,0.2)$ & $(0.5,0.3)$ & $(0.8,0.2)$ & $(0.6,0.1)$ & $(0.6,0.2)$ \\
\hline
\end{tabular}


With this information, we can make an aggregation to make a decision. First, we aggregate the information of the three experts to obtain a unified payoff matrix. We use the IFWA operator to obtain this matrix while assuming that. The results are shown in Table 4.

In this problem, the experts of the company find probabilistic information given as follows: and. Moreover, the policy of the company is to be very pessimistic whenever the future results are not clear. Therefore, they decide to manipulate the probabilities by using the following OWA weighting vector. It is now possible to develop different methods based on the IFGPOWA operator for the selection of an investment. In this example, we consider the IFPOWA, the IFA-PA, the IFA-OWA, the IFQ-OWQA, the IFQ-PQA and the IFQ-POWQA operator. The results are shown in Table 5.

As we can see, depending on the particular type of IFGPOWA operator used, the optimal choice is different. Therefore, it is interesting to establish an ordering of the investments for each particular case, then, we get the results shown in Table 6. Note that the first alternative in each ordering is the optimal choice.

Table 4. Collective results

\begin{tabular}{cccccc}
\hline & $G_{1}$ & $G_{2}$ & $G_{3}$ & $G_{4}$ & $G_{5}$ \\
\hline$A_{1}$ & $(0.50,0.38)$ & $(0.69,0.26)$ & $(0.46,0.33)$ & $(0.55,0.32)$ & $(0.62,0.33)$ \\
\hline$A_{2}$ & $(0.59,0.35)$ & $(0.63,0.23)$ & $(0.67,0.23)$ & $(0.64,0.19)$ & $(0.63,0.21)$ \\
\hline$A_{3}$ & $(0.59,0.29)$ & $(0.59,0.32)$ & $(0.68,0.20)$ & $(0.54,0.18)$ & $(0.53,0.33)$ \\
\hline$A_{4}$ & $(0.57,0.26)$ & $(0.57,0.25)$ & $(0.43,0.26)$ & $(0.62,0.20)$ & $(0.49,0.32)$ \\
\hline$A_{5}$ & $(0.63,0.18)$ & $(0.59,0.19)$ & $(0.47,0.20)$ & $(0.49,0.24)$ & $(0.61,0.29)$ \\
\hline$A_{6}$ & $(0.60,0.26)$ & $(0.60,0.27)$ & $(0.72,0.26)$ & $(0.60,0.17)$ & $(0.54,0.22)$ \\
\hline
\end{tabular}

Table 5. Aggregated results

\begin{tabular}{ccccccc}
\hline & IFPOWA & IFA-PA & IFA-OWA & IFQ-OWQA & IFQ-PQA & $\begin{array}{c}\text { IFQ- } \\
\text { POWQA }\end{array}$ \\
\hline$A_{1}$ & $(0.560,0.327)$ & $(0.575,0.320)$ & $(0.558,0.328)$ & $(0.683,0.242)$ & $(0.686,0.220)$ & $(0.680,0.227)$ \\
\hline$A_{2}$ & $(0.627,0.253)$ & $(0.630,0.247)$ & $(0.630,0.243)$ & $(0.705,0.197)$ & $(0.707,0.191)$ & $(0.707,0.189)$ \\
\hline$A_{3}$ & $(0.587,0.267)$ & $(0.596,0.263)$ & $(0.580,0.260)$ & $(0.692,0.203)$ & $(0.695,0.198)$ & $(0.687,0.198)$ \\
\hline$A_{4}$ & $(0.533,0.261)$ & $(0.542,0.256)$ & $(0.532,0.261)$ & $(0.667,0.198)$ & $(0.670,0.193)$ & $(0.666,0.198)$ \\
\hline$A_{5}$ & $(0.561,0.213)$ & $(0.569,0.208)$ & $(0.554,0.222)$ & $(0.681,0.172)$ & $(0.684,0.167)$ & $(0.675,0.179)$ \\
\hline$A_{6}$ & $(0.610,0.242)$ & $(0.620,0.241)$ & $(0.601,0.233)$ & $(0.703,0.194)$ & $(0.705,0.189)$ & $(0.700,0.187)$ \\
\hline
\end{tabular}

Table 6. Ordering of the strategies

\begin{tabular}{lclc}
\hline \multicolumn{1}{c}{ Ordering } & Ordering \\
\hline IFPOWA & $A_{2} \succ A_{6} \succ A_{5} \succ A_{3} \succ A_{4} \succ A_{1}$ & IFQ-OWQA & $A_{6} \succ A_{2} \succ A_{3} \succ A_{4} \succ A_{1} \succ A_{5}$ \\
\hline IFA-PA & $A_{2} \succ A_{6} \succ A_{5} \succ A_{3} \succ A_{4} \succ A_{1}$ & IFQ-PQA & $A_{5} \succ A_{6} \succ A_{2} \succ A_{4} \succ A_{1} \succ A_{3}$ \\
\hline IFA-OWA & $A_{2} \succ A_{6} \succ A_{5} \succ A_{3} \succ A_{4} \succ A_{1}$ & IFQ-POWQA & $A_{2} \succ A_{6} \succ A_{5} \succ A_{3} \succ A_{4} \succ A_{1}$ \\
\hline
\end{tabular}


As we can see, depending on the aggregation operators used, the ordering of the strategies is different. Therefore, the decision about which investment to select may be also different. Note that in this specific problem, we see that seems to be the optimal choice for most of the cases.

\section{Conclusions}

We have introduced a new model that unifies the probability and the OWA operator in the same formulation considering the degree of importance that each concept has in the analysis. We have called it the IFGPOWA operator. We have seen that it is able to deal with uncertain environments that can be assessed with IFNs providing a more complete representation of the decision problem. Furthermore, we have seen that this model uses generalized means providing a more robust formulation of the aggregation operator that includes a wide range of aggregation operators such as the IFPOWA, the IFPWA, the IFG-POWGA, the IFQ-POWQA, and a lot of other cases.

We have developed an application of the new approach in a financial decision making problem. We have studied an investment selection problem where a company is looking for its optimal investment. The main advantage of the IFGPOWA operator in this type of problems is that it is possible to consider a wide range of intuitionistic fuzzy aggregation operators. We have seen that depending on the particular type of IFGPOWA operator used, the results may be different.

In future research, we expect to develop further extensions to this approach by using more general formulations and considering other characteristics in the problem such as the use of order-inducing variables and distance measures. We will also consider other decision making applications such as human resource management, investment selection, and product management.

\section{Acknowledgements}

We would like to thank the anonymous referees for valuable comments that have improved the quality of the paper. This paper is supported by the MOE Project of Humanities and Social Sciences No. 14YJC910006), Zhejiang Province Natural Science Foundation (No LQ14G010002), Statistical Scientific Key Research Project of China (No. 2013LZ48), the Key Research Center of Philosophy and Social Science of Zhejiang Province - Modern Port Service Industry and Creative Culture Research Center, Philosophy and Social Science Planning Projects of Zhejiang (No. 14JDHY01YB) and Projects in Science and Technique of Ningbo Municipal (2012B82003).

\section{References}

Atanassov, K. T. 1986. Intuitionistic fuzzy sets, Fuzzy Sets and Systems 20(1): 87-96. http://dx.doi.org/10.1016/S0165-0114(86)80034-3

Atanassov, K. T.; Gargov, G. 1989. Interval-valued intuitionistic fuzzy sets, Fuzzy Sets and Systems 31(3): 343-349. http://dx.doi.org/10.1016/0165-0114(89)90205-4 
Atanassov. K. T.; Pasi, G.; Yager, R. R. 2005. Intuitionistic fuzzy interpretations of multi-criteria multi-person and multi-measurement tool decision making, International Journal of Systems Science 36(14): 859-868. http://dx.doi.org/10.1080/00207720500382365

Beliakov, G.; Pradera, A.; Calvo, T. 2007. Aggregation functions: a guide for practitioners. Berlin: Springer-Verlag.

Boran, F. E.; Genc, S.; Kurt, M.; Akay, D. 2009. A multi-criteria intuitionistic fuzzy group decision making for supplier selection with TOPSIS method, Expert Systems with Applications 36(8): 11363-11368. http://dx.doi.org/10.1016/j.eswa.2009.03.039

Calvo, T.; Mayor, G.; Mesiar, R. 2002. Aggregation operators: new trends and applications. New York: Physica-Verlag.

Chen, H. Y.; Zhou, L. G. 2011. An approach to group decision making with interval fuzzy preference relations based on induced generalized continuous ordered weighted averaging operator, Expert Systems with Applications 38(10): 13432-13440. http://dx.doi.org/10.1016/j.eswa.2011.04.175

Cheng, C. H.; Wang, J. W.; Wu, M. C. 2009. OWA-weighted based clustering method for classification problem, Expert Systems with Applications 36(3): 4988-4995. http://dx.doi.org/10.1016/j.eswa.2008.06.013

Gil-Lafuente, A. M.; Merigó, J. M. 2010. Computational intelligence in business and economics. Singapore: World Scientific.

Herrera, F.; Herrera-Viedma, E. 2000. Linguistic decision analysis: steps for solving decision problems under linguistic information, Fuzzy Sets and Systems 115(1): 67-82.

http://dx.doi.org/10.1016/S0165-0114(99)00024-X

Li, D. F. 2008. Extension of the LINMAP for multiattribute decision making under Atanassov's intuitionistic fuzzy environment, Fuzzy Optimization and Decision Making 7(1): 17-34. http://dx.doi.org/10.1007/s10700-007-9022-x

Liu, H. W. 2007. Multi-criteria deicision-making methods based on intuitionistic fuzzy sets, European Journal of Operational Research 179(1): 220-233. http://dx.doi.org/10.1016/j.ejor.2006.04.009

Liu, P. D. 2011. A weighted aggregation operators multi-attribute group decision making method based on interval-valued trapezoidal fuzzy numbers, Expert Systems with Applications 38(2): 1053-1060. http://dx.doi.org/10.1016/j.eswa.2010.07.144

Liu, P. D.; Jin, F. 2012a. Methods for aggregating intuitionistic uncertain linguistic variables and their application to group decision making, Information Sciences 205(1): 58-71.

http://dx.doi.org/10.1016/j.ins.2012.04.014

Liu, P. D.; Jin, F. 2012b. The trapezoid fuzzy linguistic Bonferroni mean operators and their application to multiple attribute decision making, Scientia Iranica E 19(6): 1947-1959.

http://dx.doi.org/10.1016/j.scient.2012.06.028

Liu, P. D.; Jin, F. 2012c. A multi-attribute group decision-making method based on weighted geometric aggregation operators of interval-valued trapezoidal fuzzy numbers, Applied Mathematical Modelling 36(6): 2498-2509. http://dx.doi.org/10.1016/j.apm.2011.09.006

Liu, P. D.; Zhang, X.; Jin, F. 2012. A multi-attribute group decision-making method based on interval-valued trapezoidal fuzzy numbers hybrid harmonic averaging operators, Journal of Intelligent \& Fuzzy Systems 23(5): 159-168. http://dx.doi.org/10.3233/IFS-2012-0505

Liu, P. D.; Su, Y. 2010. The multiple attribute decision making method based on the TFLHOWA operator, Computers and Mathematics with Applications 60(9): 2609-2615. http://dx.doi.org/10.1016/j.camwa.2010.08.087

Liu, X. 2008. A general model of parameterized OWA aggregation with given orness level, International Journal of Approximate Reasoning 48(2): 598-627. http://dx.doi.org/10.1016/j.ijar.2007.11.003

Merigó, J. M. 2010. Fuzzy decision making with immediate probabilities, Computers \& Industrial Engineering 58(4): 651-657. http://dx.doi.org/10.1016/j.cie.2010.01.007 
Merigó, J. M. 2011a. Fuzzy multi-person decision making with fuzzy probabilistic aggregation operators, International Journal of Fuzzy Systems 13(3): 163-174.

Merigó, J. M. 2011b. The uncertain probabilistic weighted average and its application in the theory of expertons, African Journal of Business Managemen 5(15): 6092-6102.

Merigó, J. M. 2012a. The probabilistic weighted average and its application in multiperson decision making, International Journal of Intelligent Systems 27(5): 457-476. http://dx.doi.org/10.1002/int.21531

Merigó, J. M. 2012b. Probabilities in the OWA operator, Expert Systems with Application 39(13): 1145611467. http://dx.doi.org/10.1016/j.eswa.2012.04.010

Merigó J. M.; Casanovas, M. 2010. Decision making with distance measures and linguistic aggregation operators, International Journal of Fuzzy Systems 12(3): 190-198.

Merigó J. M.; Casanovas, M. 2011a. Decision making with distance measures and induced aggregation operators, Computers \& Industrial Engineering 60(1): 66-76. http://dx.doi.org/10.1016/j.cie.2010.09.017

Merigó J. M.; Casanovas, M. 2011b. The uncertain induced quasi-arithmetic OWA operator, International Journal of Intelligent Systems 26(1): 1-24. http://dx.doi.org/10.1002/int.20444

Merigó, J. M.; Casanovas, M.; Engemann, K. J. 2012. Group decision-making with generalized and probabilistic aggregation operators, International Journal of Innovative Computing, Information and Control 8(7): 4823-4840.

Merigó, J. M.; Gil-Lafuente, A. M. 2010. New decision making techniques and their application in the selection of financial products, Information Sciences 180(11): 2085-2094. http://dx.doi.org/10.1016/j.ins.2010.01.028

Merigó, J. M.; Wei, G. W. 2011. Probabilistic aggregation operators and their application in uncertain multi-person decision making, Technological and Economic Development of Economy 17(2): 335-351. http://dx.doi.org/10.3846/20294913.2011.584961

Szmidt, E.; Kacprzyk, J. 2003. A consensus-reaching process under intuitionistic fuzzy preference relations, International Journal of Intelligent Systems 18(1): 837-852. http://dx.doi.org/10.1002/int.10119

Tan, C. Q.; Chen, X. H. 2010. Intuitionistic fuzzy Choquet integral operator for multi-criteria decision making, Expert Systems with Applications 37(1): 149-157. http://dx.doi.org/10.1016/j.eswa.2009.05.005

Wei, G. W. 2008. Maximizing deviation method for multiple attribute decision making in intuitionistic fuzzy setting, Knowledge-Based Systems 21(8): 833-836. http://dx.doi.org/10.1016/j.knosys.2008.03.038

Wei, G. W. 2010a. Some induced geometric aggregation operators with intuitionistic fuzzy information and their application to group decision making, Applied Soft Computing 10(2): 423-431. http://dx.doi.org/10.1016/j.asoc.2009.08.009

Wei, G. W. 2010b. GRA method for multiple attribute decision making with incomplete weight information in intuitionistic fuzzy setting, Knowledge-Based Systems 23(3): 243-247.

http://dx.doi.org/10.1016/j.knosys.2010.01.003

Wei, G. W.; Merigó, J. M. 2012. Methods for strategic decision-making problems with immediate probabilities in intuitionistic fuzzy setting, Scientia Iranica E 19(6): 1936-1946. http://dx.doi.org/10.1016/j.knosys.2010.01.003

Xu, Y. J.; Wang, H. M. 2011. Approaches based on 2-tuple linguistic power aggregation operators for multiple attribute group decision making under linguistic environment, Applied Soft Computing 11(5): 3988-3997. http://dx.doi.org/10.1016/j.asoc.2011.02.027

$\mathrm{Xu}$, Y. J.; Wang, H. M. 2012. The induced generalized aggregation operators for intuitionistic fuzzy sets and their application in group decision making, Applied Soft Computing 12(3): 1168-1179. http://dx.doi.org/10.1016/j.asoc.2011.11.003

$\mathrm{Xu}, \mathrm{Z}$. S. 2005. An overview of methods for determining OWA weights, International Journal of Intelligent Systems 20(8): 843-865. http://dx.doi.org/10.1002/int.20097 
Xu, Z. S. 2007a. Intuitionistic fuzzy aggregation operators, IEEE Transactions on Fuzzy Systems 15(6): 1179-1187. http://dx.doi.org/10.1109/TFUZZ.2006.890678

$\mathrm{Xu}, \mathrm{Z}$. S. 2007b. Some similarity measures of intuitionistic fuzzy sets and their applications to multiple attribute decision making, Fuzzy Optimization and Decision Making 6(2): 109-121. http://dx.doi.org/10.1007/s10700-012-9135-8

$\mathrm{Xu}, \mathrm{Z}$. S. 2007c. Intuitionistic preference relations and their application in group decision making, Information Sciences 177(11): 2363-2379. http://dx.doi.org/10.1016/j.ins.2006.12.019

Xu, Z. S. 2010a. A method based on distance measure for interval-valued intuitionistic fuzzy group decision making, Information Sciences 180(1): 181-190. http://dx.doi.org/10.1016/j.ins.2009.09.005

Xu, Z. S. 2010b. A deviation-based approach to intuitionistic fuzzy multiple attribute group decision making, Group Decision and Negotiation 19(1): 57-76. http://dx.doi.org/10.1007/s10726-009-9164-Z

$\mathrm{Xu}, \mathrm{Z}$. S. 2011. Approaches to multiple attribute group decision making based on intuitionistic fuzzy power aggregation operators, Knowledge-Based Systems 24(6): 749-760. http://dx.doi.org/10.1016/j.knosys.2011.01.011

Xu, Z. S.; Cai, X. Q. 2009. Incomplete interval-valued intuitionistic preference relations, International Journal of General Systems 38(8): 871-886. http://dx.doi.org/10.1080/03081070903210630

Xu, Z. S.; Cai, X. Q. 2010. Nonlinear optimization models for multiple attribute group decision making with intuitionistic fuzzy information, International Journal of Intelligent Systems 25(6): 489-513. http://dx.doi.org/10.1002/int.20409

Xu, Z. S.; Chen, J. 2008. Ordered weighted distance measure, Journal of Systems Science and Systems Engineering 17(4): 432-445. http://dx.doi.org/10.1007/s11518-008-5084-8

Xu, Z. S.; Da, Q. L. 2003. An overview of operators for aggregating information, International Journal of Intelligent Systems 18(9): 953-968. http://dx.doi.org/10.1002/int.10127

$\mathrm{Xu}$, Z. S.; Xia, M. 2010. Induced generalized intuitionistic fuzzy operators, Knowledge-Based Systems 24(2): 197-209. http://dx.doi.org/10.1016/j.knosys.2010.04.010

Xu, Z. S.; Yager, R. R. 2006. Some geometric aggregation operators based on intuitionistic fuzzy sets, International Journal of General Systems 35(4): 417-433. http://dx.doi.org/10.1080/03081070600574353

Yager, R. R. 1988. On ordered weighted averaging aggregation operators in multicriteria decision making, IEEE Transactions on Systems, Man and Cybernetics B 18(1): 183-190. http://dx.doi.org/10.1109/21.87068

Yager, R. R. 1996. On the inclusion of variance in decision making under uncertainty, International Journal of Uncertainty, Fuzziness and Knowledge-Based System 4(5): 401-419. http://dx.doi.org/10.1142/S0218488596000238

Yager, R. R. 2004. Generalized OWA aggregation operators, Fuzzy Optimization and Decision Making 3(1): 93-107. http://dx.doi.org/10.1023/B:FODM.0000013074.68765.97

Yager, R. R. 2006. Generalizing variance to allow the inclusion of decision attitude in decision making under uncertainty, International Journal of Approximate Reasoning 42(3): 137-158. http://dx.doi.org/10.1016/j.ijar.2005.09.001

Yager, R. R. 2007. Centered OWA operators, Soft Computing 11(7): 631-639. http://dx.doi.org/10.1007/s00500-006-0125-z

Ye, J. 2009. Multicriteria fuzzy decision-making method based on a novel accuracy function under interval-valued intuitionistic fuzzy environment, Expert Systems with Applications 36(3): 6899-6902. http://dx.doi.org/10.1016/j.eswa.2008.08.042

Ye, J. 2010. Fuzzy decision-making method based on the weighted correlation coefficient under intuitionistic fuzzy environment, European Journal of Operational Research 205(1): 202-204. http://dx.doi.org/10.1016/j.ejor.2010.01.019

Zadeh, L. A. 1965. Fuzzy sets, Information Control 8: 338-353. http://dx.doi.org/10.1016/S0019-9958(65)90241-X 
Zarghami, M.; Szidarovszky, F. 2009. Revising the OWA operator for fuzzy stochastic multi criteria decision making, European Journal of Operational Research 198(1): 259-265.

http://dx.doi.org/10.1016/j.ejor.2008.09.014

Zeng, S. Z. 2013. Some intuitionistic fuzzy weighted distance measures and their application to group decision making, Group Decision and Negotiation 22(2): 281-298.

http://dx.doi.org/10.1007/s10726-011-9262-6

Zeng, S. Z.; Su, W. H. 2011. Intuitionistic fuzzy ordered weighted distance operator, Knowledge-Based Systems 24(8): 1224-1232. http://dx.doi.org/10.1016/j.knosys.2011.05.013

Zeng, S. Z.; Su, W. H. 2012. Linguistic induced generalized aggregation distance operators and their application to decision making, Economic Computer and Economic Cybernetics Studies and Research 46(2): 155-172.

Zeng, S. Z.; Su, W. H.; Le, A. B. 2012. Fuzzy generalized ordered weighted averaging distance operator and its application to decision making, International Journal of Fuzzy Systems 14(3): 366-377.

Zeng, S. Z.; Merigó, J. M.; Su, W. H. 2013. The uncertain probabilistic OWA distance operator and its application in group decision making, Applied Mathematical Modelling 37(9): 6266-6275. http://dx.doi.org/10.1016/j.apm.2013.01.022

Zhao, H.; Xu, Z. S.; Ni, M. F.; Liu, S. S. 2010. Generalized aggregation operators for intuionistic fuzzy sets, Internation Journal of Intelligent Systems 25(1): 1-30. http://dx.doi.org/10.1002/int.20386

Zhou, L. G.; Chen, H. Y. 2010. Generalized ordered weighted logarithm aggregation operators and their applications to group decision making, International Journal of Intelligent Systems 25(7): 683-707. http://dx.doi.org/10.1002/int.20419

Zhou, L. G.; Chen, H. Y. 2011. Continuous generalized OWA operator and its application to decision making, Fuzzy Sets and Systems 168(1): 18-34. http://dx.doi.org/10.1016/j.fss.2010.05.009

Shouzhen ZENG was born in 1981. He has a MS degree in applied mathematics obtained in 2007 from Tianjin University, China. He received a PhD degree in statistics from Zhejiang Gongshang University in 2013. He has published more than 40 papers in journals, books and conference proceedings including journals such as Statistics Research, Knowledge-Based Systems, Applied Mathematical Modelling and Group Decision and Negotiation. He has participated in several scientific committees and serves as a reviewer in a wide range of journals including Computers \& Industrial Engineering, International Journal of Fuzzy Systems and European Journal of Operational Research. His main research fields are aggregation operators, decision making, comprehensive evaluation and uncertainty.

Weihua SU has an MSc and a PhD degree in statistics from Xiamen University, China. He is a Professor in College of Mathematics and Statistics, Zhejiang University of Finance and Economics. He has published more than 90 papers in journals, books and conference proceedings including journals such as Statistics Research, International Journal of Fuzzy Systems, Knowledge-based Systems and Applied Mathematical Modelling. He has published 3 books. His current research interests are aggregation operators, decision making and comprehensive evaluation.

Chonghui ZHANG graduated from the Zhejiang Gongshang University and obtained a Master's degree in applied economics in 2013. At present, he is studying his $\mathrm{PhD}$ degree in statistics at Zhejiang Gongshang University. He has published more than 10 papers in journals, books and conference proceedings including journals such as Statistics Research and International Journal of Uncertainty, Fuzziness and Knowledge-Based Systems. His main research fields are decision making, comprehensive evaluation and income distribution. 